\title{
Overweight, Diet, Physical Activity, and Hypertension in Low-Income School-Aged Children
}

\author{
Kelley Marty, Cindy Wolff, and Irene Morgan \\ California State University, Chico
}

\begin{abstract}
The purpose of this cross-sectional, descriptive study was to examine overweight as an independent risk factor for hypertension (HTN) in children, as well as associations among body mass index (BMI), blood pressure, diet, and physical activity. Study participants included 1,284 students in grades five to eight in three school districts in rural northern California. Analysis of variance was used to test for differences in BMI and blood pressure based on diet and physical activity. Pearson's correlation was used to assess the relationships among blood pressure, BMI, dietary, and physical activity variables. Multiple regression analysis was used to determine independent risk factors for BMI and systolic blood pressure. Forty-four percent of the students were $\geq 85$ th percentile BMI-for-age. With one blood pressure reading, $28 \%$ met the criteria for either pre-hypertension or hypertension using standardized criteria for age, gender, and height. HTN rates were significantly higher for overweight vs. normal weight children $(p=.001)$. Fruit and vegetable intake decreased significantly by grade $(\mathrm{p}=.001)$. Regression results showed that soda consumption was an independent risk factor for BMI $(\mathrm{p}=.001)$ and that BMI was an independent risk factor for HTN $(p=.001)$. Findings support the need for nutrition education and physical activity promotion programs in these three school districts.
\end{abstract}

(C) 2006 Californian Journal of Health Promotion. All rights reserved.

Keywords: Child overweight, child hypertension, diet, physical activity, low-income

\section{Introduction}

The prevalence of childhood overweight has increased strikingly over the last two decades (CDC, 2000). Overweight is defined by the Center for Disease Control and Prevention (CDC) as a Body Mass Index (BMI)-for-age $>95$ th percentile, specific for gender. Utilizing NHANES data, Ogden and coworkers reported that $15 \%$ of six- to eleven-year-old children and $16 \%$ of 12 - 19 year old adolescents are overweight in the United States (Ogden, Flegal, Carroll, Johnson, 2002). In addition, approximately $15 \%$ of children and adolescents are at-risk for overweight, defined by the CDC as between the 85th and 95th percentile BMIfor-age, specific for gender. The California Center for Public Health Advocacy (CCPHA) analyzed data from the California Department of Education's 2001 California Physical Fitness Test and reported that $27 \%$ of California's youth (5th, 7th, and 9th graders) are overweight or atrisk for overweight (CCPHA, 2002). These data are organized and reported by legislative districts. Assembly District 3, which encompasses the residential area of the study participants, reported that $20 \%$ of 5 th, 7 th, and 9 th grade children are overweight or at-risk for overweight and $30 \%$ are unfit.

The National Heart, Lung, and Blood Institute (NHLBI) and National High Blood Pressure Education Program (NHBPEP) released updated US guidelines for hypertension (HTN) and prehypertension (pre-HTN) in children and adolescents in 2004 (NHLBI, 2004). The new guidelines stress that both HTN and pre-HTN are significant health concerns.

Mutner and colleagues used representative samples of children and adolescents, aged eight - 17 years, from NHANES III conducted in 1988-1994 $(\mathrm{n}=3496)$ and NHANES 1999-2000 $(n=2086)$ to examine trends in blood pressure over the last decade (Muntner, He, Cutler, 
Wildman, Whelton, 2004). These researchers found that along with the increasing prevalence of overweight, blood pressure in children has also increased. Several large studies report that overweight children and adolescents are more likely to have elevated blood pressure levels (Freedman, Dietz, Srinivasan, Berenson, 1999; Sorof, Poffenbarger, Franco, Bernard, Portman, 2002; Sorof, Lai, Turner, Poffenbarger, Portman, 2004).

Researchers have reported a reduced prevalence of HTN in adults consuming a diet high in fruits and vegetables with the most well known study being the Dietary Approaches to Stop Hypertension (DASH) trail. Both the high fruit and vegetable diet (eight to 10 servings of fruit and vegetables daily) and the DASH eating plan (high in fruits, vegetables, low-fat dairy and low in saturated and total fat) significantly reduced blood pressure levels (Appel, Moore, Obarzanek, Vollmer, Svetkey, Sacks et al., 1997). There is a dearth of studies that investigate specifically fruit and vegetable consumption and the association with the prevalence of high blood pressure among youth. Simons-Morton and colleagues found that both systolic (SBP) and diastolic blood pressure (DBP) levels were inversely associated with specific micronutrients (calcium, magnesium, and potassium) and fiber in 662 children aged eight - eleven years who had elevated LDL cholesterol levels (Simons-Morton, Hunsberger, Van Horn, Barton, Robson, McMahon et al., 1997). Fruits and vegetables can be rich sources of micronutrients and fiber. In a more recent study, Moore and coworkers (2005) reported similar associations between blood pressure and diet in youth. Utilizing eight years of follow-up data from the Framingham Children's study (1986), which consisted of 95 children initially three - five years of age, researchers reported children consuming more fruits and vegetables or more dairy products during the preschool years had smaller yearly SBP gains throughout childhood. When reaching early adolescence, children with a higher consumption of fruits, vegetables, and dairy products had an adjusted mean SBP $(106 \pm 2.9 \mathrm{mmHg})$ lower than that of children who consumed lower intakes $(113 \pm 1.5$
$\mathrm{mmHg}$ (Moore, Singer, Bradlee, Djousse, Proctor, Cupples et al., 2005).

Fruit and vegetables are part of a healthy diet and appear to reduce future risk of chronic disease, such as certain cancers and cardiovascular disease (Hyson, 2004). Results from the 1994-1996 Continuing Survey of Food Intakes by Individuals (CSFII) indicate that U.S. children come up short of fruit and vegetable recommendations. Assessed through two 24hour recall in-person interviews, daily fruit and vegetable consumption averaged 3.8 servings among six to eleven year old boys and 3.7 servings among six to eleven year old girls $(n=1311)$ (USDA, 1996). Findings from the 1999 California Children's Healthy Eating and Exercise Practices Survey (CalCHEEPS), which utilized a two-day food diary, showed that California children, ages nine to eleven years old, were consuming an average of 3.2 servings of fruits and vegetables on a usual school day, and only one fifth of these children ate the recommended five servings per day (Keihner, Garbolino, Hudes, 2004).

Soda consumption has increased dramatically in the last 20 years (Calvadini, Siega-Riz, Popkin, 2000). Ludwig and colleagues' longitudinal trial results indicate that children with higher soda and other sugar-sweetened beverage intake have higher BMIs than children with lower intakes (Ludwig, Peterson, Gortmaker, 2001). Similarly, Berkey and coworkers reported the consumption of sugar-sweetened beverages was associated with BMI gains during the corresponding year in a prospective cohort study of nine- to fourteenyear-old boys and girls participating in the U.S. Growing Up Today Study (Berkey, Rockett, Field, Gillman, Colditz, 2004). In addition, a positive association has been observed between soda and blood pressure in adolescents, such that high soda consumption rates are associated with higher blood pressure values. The authors suggest that the caffeine in sodas may increase blood pressure and, thereby, increase the risk of HTN (Savoca, Evans, Wilson, Harshfield, Ludwig, 2004).

While physical activity has many benefits, physical inactivity is associated with negative 
health implications. According to the American Heart Association (AHA), physical inactivity is a major risk factor for coronary artery disease. It also increases the risk of stroke and other major cardiovascular risk factors including obesity, high blood pressure, and diabetes. The AHA recommends that children and adolescents participate in at least 60 minutes of moderate to vigorous physical activity every day (AHA, 2004).

The Youth Risk Behavior Surveillance System (YRBSS) results indicate that $33 \%$ of U.S. students in grades nine to twelve had not participated in either sufficient vigorous or moderate physical activity during the seven days preceding the survey (CDC, 2004). According to 1999 CalCHEEPS data, only $46 \%$ of Californian children were getting an average of 60 minutes of moderate and vigorous physical activity combined daily (Keihner, Foerster, Sugerman, Oppen, Hudes, 2002). Additionally, in 2002 the California Center for Public Health Advocacy (CCPHA) reported that $40 \%$ of Californian 5th, 7th, and 9th graders were unfit. As stated previously, $30 \%$ of children in Assembly District 3, which encompasses the residential area of the study participants, are unfit (CCPHA, 2002).

The current study assessed the rate of overweight, HTN, and pre-HTN in ten lowincome schools from three school districts in rural Northern California. The primary purpose of this study was to examine overweight as an independent risk factor for HTN and pre-HTN in children. A secondary purpose was to examine associations among soda and fruit and vegetable consumption, level of physical activity, body mass index, and blood pressure.

\section{Methods}

\section{Selection}

Study Participants and Method of

For this cross-sectional descriptive study, a school-based health screening was performed on 1,284 students in grades five through eight from ten schools in three different school districts in rural northern California. Participating schools represent a variety of ethnicities reflective of the ethnic make-up of the geographical area. Only those students who returned a signed parental permission slip were able to participate. This research was approved by the California State University, Chico Human Subjects Committee.

\section{Procedures \\ Data Collection Instrument and}

A lifelong eating and activity patterns questionnaire was used to collect information on gender, ethnicity, and date of birth, as well as several questions and Likert statements concerning dietary consumption and physical activity levels. The survey questionnaire was field-tested for face and content validity and refined based on the results of this field-test. Trained researchers provided assistance and clarification to the students during the completion of the lifelong eating and activity patterns questionnaire when needed. Height and weight were measured by trained researchers for each student and BMI $\left(\mathrm{kg} / \mathrm{ht}^{2}\right)$ was then calculated. The scale used was a standard medically approved dial scale with weight measured to the nearest whole pound. Height was measured with a standiometer and reported in inches to the nearest quarter inch. BMI percentile, age and gender specific, was determined using the most current pediatric anthropometric reference data (Kuczmarski, Ogden, Grummer-Strawn, 2000). Overweight is defined by the CDC as BMI-for-age $>95$ th percentile and at-risk for overweight is defined as BMI-for-age $>85$ th percentile.

A trained researcher or school nurse took blood pressure measurements. Blood pressure was taken while the participants were seated and after the completion of the questionnaire to assure that heart rate was at a resting rate. Three different sized cuffs were available for use, with the appropriate sized cuff being utilized for each participant. If the blood pressure reading was elevated, the measurement was repeated a second time. HTN is defined as systolic blood pressure (SBP) and/or diastolic blood pressure (DBP) $>95$ th percentile for age, gender, and height measured on three distinct occasions. PreHTN is defined as SBP and/or DBP between the 90th and 95th percentiles for age, gender, and height (NHLBI, 2004). 


\section{Statistical Analysis}

Data were analyzed using the Statistical Package for the Social Sciences (version 11.0, 2001, SPSS, Inc, Chicago, IL). Descriptive statistics are presented as counts, percentages, and means \pm standard deviations. Chi square was used to examine differences between groups for a variety of selected variables. An independent samples $\mathrm{t}$-test was used to assess for significant differences in mean BMI for students consuming greater than two sodas per day vs. those consuming less than two sodas per day. Analysis of variance (ANOVA) was used to test for differences in BMI and blood pressure based on fruit, vegetable, and soda consumption and physical activity patterns. Pearson's correlation coefficient was used to test for correlations among blood pressures, BMI, physical activity level, and fruit, vegetable, and soda consumption and multiple regression analysis was used to predict SBP and BMI from demographic, dietary, and physical activity variables. Statistical significance was assessed at $\mathrm{p}<.05$.

\section{Results}

Participant characteristics are shown in Table 1. The sample was $52 \%$ male and $48 \%$ female. Thirty-one percent of the participants were enrolled in the fifth grade $(n=396), 14 \%$ in the sixth grade $(\mathrm{n}=182), 25 \%$ in the seventh grade $(n=322)$, and $30 \%$ in the eighth grade $(n=384)$. The racial/ethnic composition of the sample was $43 \%$ Caucasian $(n=509), 28 \%$ Hispanic $(n=328)$, $18 \%$ Asian $(\mathrm{n}=210), 5 \%$ Native American $(\mathrm{n}=61), 3 \%$ African American $(\mathrm{n}=38)$, and 4\% Other $(\mathrm{n}=44)$.

Table 1

Participant characteristics ( $\mathrm{n}$ varies between 1,190 and 1,284)

\begin{tabular}{|l|c|c|}
\hline \multicolumn{1}{|c|}{ Demographic } & Number & Percent \\
\hline Gender & & \\
\hline Male & 646 & 52 \\
\hline Female & 607 & 48 \\
\hline School District & & \\
\hline Chico & 309 & 24 \\
\hline Thermalito & 361 & 28 \\
\hline Gridley & 614 & 48 \\
\hline Grade Level & & \\
\hline 5th & 396 & 31 \\
\hline 6th & 182 & 14 \\
\hline 7th & 322 & 25 \\
\hline 8th & 384 & 30 \\
\hline Ethnic Group & & \\
\hline Caucasian & 509 & 43 \\
\hline Mexican-American & 328 & 28 \\
\hline Asian & 210 & 18 \\
\hline Native American & 61 & 5 \\
\hline African American & 38 & 3 \\
\hline Other & 44 & 4 \\
\hline
\end{tabular}

BMI characteristics for participants are shown in Figure 1. Fifty-six percent $(n=705)$ of the participants were of normal weight (BMI-forage $<84.9$ th percentile $), 20 \%(n=253)$ were atrisk for overweight (BMI-for-age $>85$ th -94.9 th percentile), and $24 \%(n=308)$ were overweight (BMI-for-age $>95$ th percentile). Hence, $44 \%$ of the study subjects were $>85$ th percentile BMIfor-age. 
For the sub-sample of students assessed for blood pressure $(\mathrm{n}=881)$, mean SBP was $109.4 \pm$ $12.6 \mathrm{mmHg}$ and mean DBP was $66.7 \pm 9.2$ $\mathrm{mmHg}$ (Table 2). Based on this single reading, $14 \%(n=122)$ had systolic and/or diastolic values indicative of pre-HTN $(90-94.9$ th percentile $)$. An additional 14\% $(n=123)$ had systolic and/or diastolic values indicative of HTN ( $>95$ th percentile).

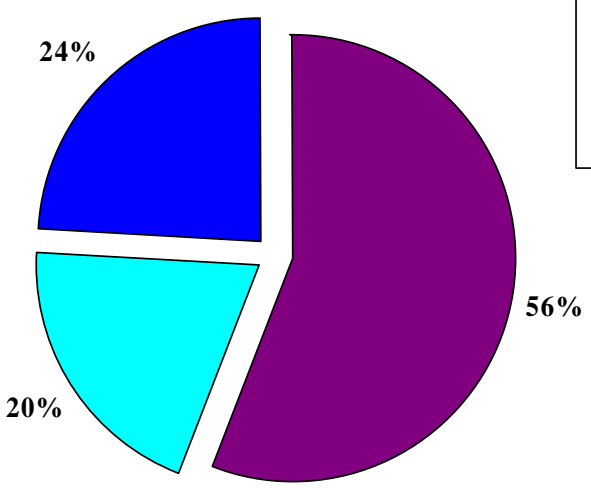

$\square$ Normal weight

$\square$ At-risk for Overweight

Overweight

Figure 1

Body mass index characteristics of school-age children $(n=1,266)$

Table 2

Blood pressure characteristics of school age children $(n=881)^{\mathrm{a}}$

\begin{tabular}{|c|c|c|c|}
\hline Blood Pressure Characteristics & Mean \pm SD & Number & Percent \\
\hline Systolic Blood Pressure & $109.4 \pm 12.6$ & & \\
\hline$<50^{\text {th }}$ percentile $^{\mathrm{b}}$ & & 334 & 38 \\
\hline$\geq 50$ th $-89.9^{\text {th }}$ percentile $^{\mathrm{b}}$ & & 361 & 42 \\
\hline$\geq 90$ th $-94.9^{\text {th }}$ percentile & & 71 & 8 \\
\hline$\geq 95^{\text {th }}$ percentile ${ }^{\mathrm{d}}$ & & 104 & 12 \\
\hline Diastolic Blood Pressure & $66.9 \pm 9.2$ & & \\
\hline$<50^{\text {th }}$ percentile $^{\text {b }}$ & & 262 & 30 \\
\hline$\geq 50$ th $-89.9^{\text {th }}$ percentile ${ }^{b}$ & & 481 & 55 \\
\hline$\geq 90$ th $-94.9^{\text {th }}$ percentile $^{\mathrm{c}}$ & & 83 & 10 \\
\hline$\geq 95^{\text {th }}$ percentile $^{\mathrm{d}}$ & & 43 & 5 \\
\hline \multicolumn{4}{|l|}{ Blood Pressure Category } \\
\hline$<50^{\text {th }}$ percentile $^{\text {b }}$ & & 127 & 15 \\
\hline$\geq 50$ th $-89.9^{\text {th }}$ percentile ${ }^{b}$ & & 497 & 57 \\
\hline$\geq 90$ th $-94.9^{\text {th }}$ percentile ${ }^{\mathrm{c}}$ & & 122 & 14 \\
\hline$\geq 95^{\text {th }}$ percentile $^{\mathrm{d}}$ & & 123 & 14 \\
\hline
\end{tabular}


At $24 \% \quad(n=13)$ and $20 \% \quad(n=11)$, Native Americans had significantly higher rates of preHTN and HTN, respectively, compared to all other ethnicities $(\mathrm{p}=.001)$. In comparison, rates of pre-HTN and HTN varied between $11-14 \%$ and $11-18 \%$, respectively for Caucasian, Asian, and Hispanic participants.

As shown in Figure 2, rates for HTN ( $>95$ th percentile) and pre-HTN (85th - 94.9 percentile) were significantly higher for overweight (BMIfor-age $>85$ th percentile) vs. normal weight children $(\mathrm{p}=.001)$. Of the $14 \%$ of the sample in the pre-HTN group, approximately $65 \%$ were $>$ 85 th percentile BMI-for-age, and of the additional $14 \%$ who were in the HTN group, $78 \%$ were $>85$ th percentile BMI-for-age.
One-way ANOVA results indicated that fruit and vegetable intake differed significantly by grade, such that as grade increased, consumption decreased $(\mathrm{P}=.001)$. Post-hoc comparisons indicated that the number of fruit servings per day for eighth graders $(2.6 \pm 1.0)$ was significantly less than that of seventh $(3.0 \pm 1.1)$, sixth $(3.0 \pm 1.2)$, and fifth graders $(3.3 \pm 1.3)$, and fifth graders' intake was significantly higher than the other three grades (Fig. 3). Post-hoc comparisons also indicated that the number of vegetable servings per day for eighth graders $(2.2 \pm 1.2)$ was significantly less than that of seventh $(2.6 \pm 1.1)$, sixth $(2.6 \pm 1.2)$, and fifth graders $(2.7 \pm 1.4)$. Grades denoted with different letters in Figure 3 are significantly different with regard to number of fruit and vegetable servings per day.

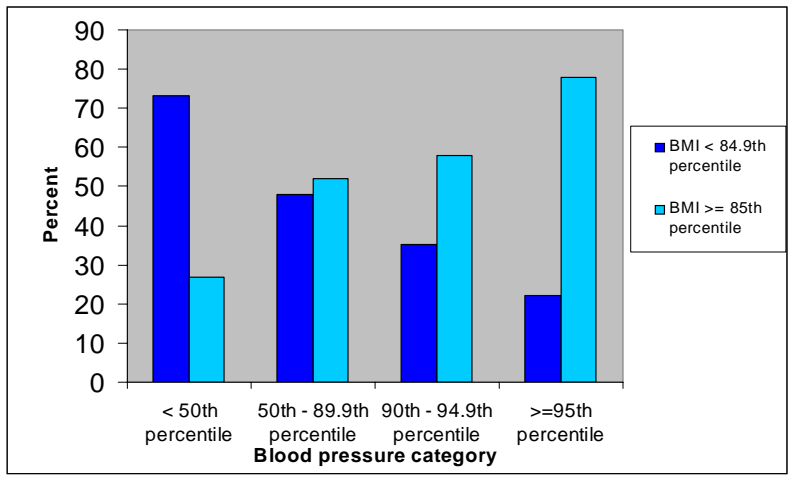

Figure 2

Blood pressure category rates for BMI groups $(p=.001)$

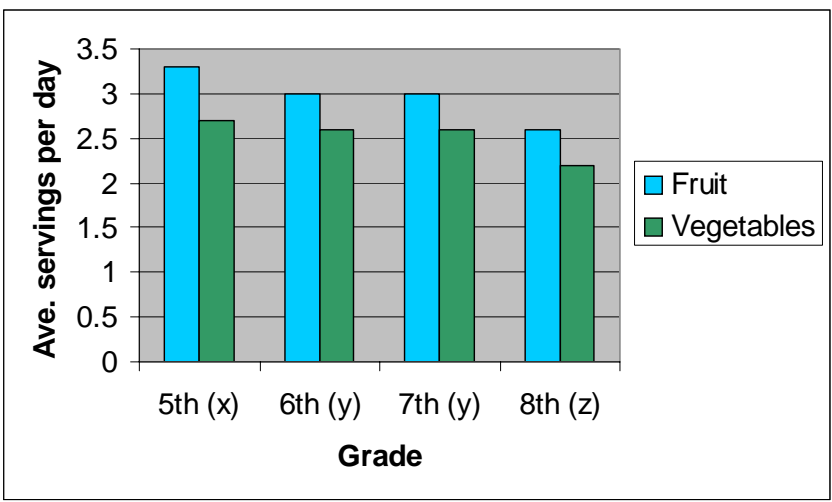

Figure 3

Fruit and vegetable intake by grade level $(p=.001)$ 
Bivariate correlations were computed between BMI, SBP, and the following lifestyle statements: "I usually eat __ fruit servings per day.", "I usually eat _ vegetable servings per day.", "I usually drink _ regular sodas per day.", and the Likert statement, "I usually get at least one hour of physical activity per day." The results are shown in Table 3. A moderate, positive correlation was seen between BMI and SBP, such that as BMI increased, SBP increased $(\mathrm{r}=.45, \mathrm{p}=.001)$. BMI was inversely correlated with fruit consumption $(r=-.08, p=.027)$, vegetable consumption $(\mathrm{r}=-.08, \mathrm{p}=.025)$, and physical activity $(\mathrm{r}=-.12, \mathrm{p}=.001)$, such that as fruit and vegetable consumption and physical activity level decreased, BMI increased. A positive association was observed between BMI and soda consumption, such that as soda consumption increased, BMI also increased ( $\mathrm{r}=$ $.20, \mathrm{p}=.002)$. SBP was also positively associated with soda consumption, such that as soda consumption increased, SBP increased $(r=.19$, $\mathrm{p}=.003$ ), and negatively associated with fruit consumption, such that as fruit consumption decreased, SBP increased $(\mathrm{r}=-.12, \mathrm{p}=.013)$. Both fruit and vegetable consumption were positively correlated with the statement "I usually get at least one hour of physical activity per day." $(\mathrm{r}=.15, \mathrm{p}=.001$ and $\mathrm{r}=.15, \mathrm{p}=.001$, respectively). In contrast, soda consumption was inversely associated with physical activity levels $(\mathrm{r}=-.27, \mathrm{p}=.001)$.

Table 3

Correlations among BMI, systolic blood pressure, diet, and physical activity

\begin{tabular}{|c|c|c|c|c|c|}
\hline & BMI & SBP & $\begin{array}{l}\text { I usually eat } \\
\text { fruit } \\
\text { servings/day }\end{array}$ & $\begin{array}{l}\text { I usually eat } \\
\text { veg. } \\
\text { servings/day }\end{array}$ & $\begin{array}{l}\text { I usually } \\
\text { drink } \\
\text { regular } \\
\text { sodas/day }\end{array}$ \\
\hline \multicolumn{6}{|l|}{ BMI } \\
\hline SBP & $.448 * *$ & & & & \\
\hline $\begin{array}{l}\text { I usually eat___ fruit } \\
\text { servings/day }\end{array}$ & $-.076^{*}$ & $-.109^{*}$ & & & \\
\hline $\begin{array}{l}\text { I usually eat __ veg. } \\
\text { servings/day }\end{array}$ & $-.077^{*}$ & -.057 & $.537^{* *}$ & & \\
\hline $\begin{array}{l}\text { I usually drink __ regular } \\
\text { sodas/day }\end{array}$ & $.202 *$ & $.194 * *$ & $-.222 * *$ & $-.197 * *$ & $.202 *$ \\
\hline $\begin{array}{l}\text { I usually get } \geq 1 \mathrm{hr} \text {. of physical } \\
\text { activity/day }\end{array}$ & $-.129 * *$ & -.081 & $.152 * *$ & $.154 * *$ & $-.269^{* *}$ \\
\hline
\end{tabular}

${ }^{*} \mathrm{p}<.05,{ }^{* *} \mathrm{p}<.01,{ }^{* * *} \mathrm{p}<.001$.

There were significant differences in reported consumption of fruit between BMI percentile groups $(\mathrm{p}=.05)$, such that students with a BMIfor-age $>85$ th percentile consumed fewer fruit servings per day. Sixty-two percent of those with a normal BMI $(<$ 84.9th percentile) reported consuming five or more servings of fruit per day versus $19 \%$ of those between the 85 - 94.9th BMI percentile and 19\% of those greater than 95th BMI percentile. Participants who consumed greater than three servings of fruit per day had a mean BMI one unit less than those who consumed less than three fruit servings per day (21.7 vs. $22.6 ; \mathrm{P}=.017$ ).

Students who consumed greater than two sodas per day $(n=61)$ had a mean BMI 2.2 units greater than those who consumed less than two sodas per day (23.1 vs. 20.9; $\mathrm{P}=.004)$. In addition, students consuming greater than two sodas per day had a mean SBP $6.6 \mathrm{mmHg}$ higher than 
those who consumed less than two sodas per day (112.8 vs. $106.2 ; \mathrm{p}=.002)$.

There was a significant difference in usual number of minutes of physical activity per day by fruit consumption groups. Among students who reported consuming 1 serving of fruit per day, $(\mathrm{n}=81)$ approximately $31 \%$ were physically active for 60 minutes or more per day, while of those consuming three or more servings per day $(\mathrm{n}=121)$, approximately $64 \%$ reported being physically active for 60 minutes or more per day $(p=.001)$. Similar results were seen for number of minutes of physical activity per day and vegetable consumption. Among those consuming one serving of vegetables per day $(n=137)$ approximately $39 \%$ reported being physically active for 60 minutes or more per day, while for those consuming five or more servings per day $(n=75)$, approximately $65 \%$ reported being physically active for 60 minutes or more per day $(\mathrm{p}=.003)$.

As shown in Figure 4, mean BMI increased significantly as average number of minutes of physical activity per day decreased $(p=.001)$. Those students physically active for 60 minutes or more per day $(n=404)$ had a significantly lower mean BMI $(21.3+4.7)$ compared to students who were either physically active 0 29 minutes per day $(\mathrm{n}=126 ; 22.8 \pm 5.3)$ and those physically active $30-59$ minutes per day $(\mathrm{n}=321 ; 22.5 \pm 5.4)$.

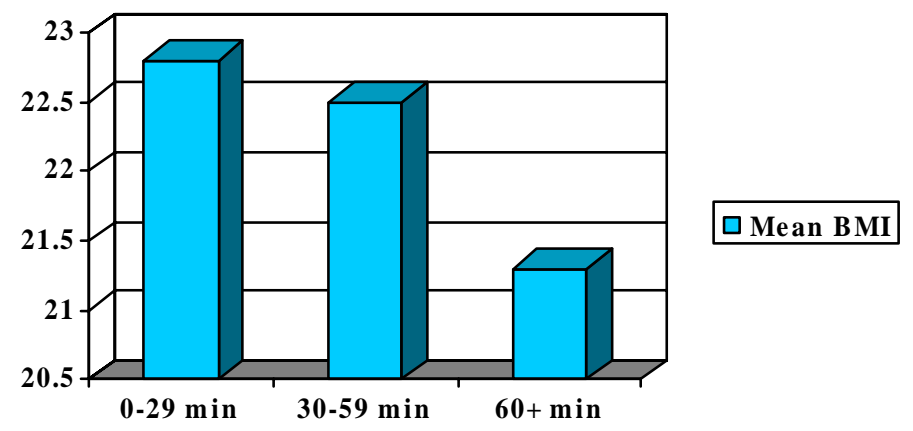

Figure 4

Mean BMI for minutes of physical activity per day groups $(\mathrm{p}=.001)$

Multiple regression was used to assess predictors of BMI. The regression model included age, gender, physical activity level in minutes per day, and usual fruit, vegetable, and soda consumption. Together these variables explained $11 \%$ of the variance in BMI, with age and soda consumption making significant independent contributions $(\mathrm{F}=14.22, \mathrm{p}=.001)$.

Multiple regression was also utilized to assess whether BMI was predictive of SBP independent of age, ethnicity, and various dietary and physical activity variables. The baseline model included BMI, age, gender, and usual soda consumption. Together these variables explained $36 \%$ of the variance in systolic blood pressure, with only BMI and age making a significant independent contribution $(\mathrm{F}=25.78, \mathrm{p}=.001)$. A secondary model with BMI and age removed showed that soda consumption is predictive of SBP in this study sample $(\mathrm{F}=9.07, \mathrm{p}=.003)$ with soda consumption explaining $4 \%$ of the variance in systolic blood pressure. 


\section{Discussion}

The results of this needs assessment revealed that the rate of pediatric overweight and at-risk for overweight in these three low-income schools is disturbingly high with $44 \%$ of participants above the 85th percentile BMI-forage. This is higher than the national average of $31 \%$ of children and adolescents $>85$ th percentile BMI-for-age (Ogden et al., 2002). It is also higher than the reported rate of overweight and at-risk for overweight among California's youth, 26.5\%, and in Assembly District 3, $19.6 \%$, according to the 2001 California Physical Fitness Test for 5th, 7th, and 9th graders (CCPHA, 2002).

Based on a single reading for the sub-sample of students assessed for blood pressure $(n=881)$, $14 \%$ had systolic and/or diastolic values indicative of pre-HTN $(90-94.9$ th percentile $)$. An additional 14\% had systolic and/or diastolic values indicative of HTN ( $>$ 95th percentile). This is less than the $19 \%>95$ th percentile reported by Sorof and coworkers (2004) for a single blood pressure reading. The differences in hypertension rates may be attributed to a higher percent of African American participants (22\%) in the Sorof et al study versus only $3 \%$ for the current study. Rates of HTN are known to be higher among African Americans (Sorof et al., 2004). No comparative data are available for rates of pre-HTN among children.

BMI was associated with all the variables included in the bivariate correlation (SBP; fruit, vegetable, and soda consumption; and physical activity). This finding and that of the regression analysis supports the research hypothesis that there would be significant associations among these variables. As stated previously, study results indicate that participants who consume greater than three servings of fruit per day have a significantly lower mean BMI compared to those who consume less than three servings per day (21.7 vs. $22.6 ; \mathrm{P}=.017)$. These results are similar to those of Bernard and colleagues, who reported that significantly fewer servings of fruit and vegetables were consumed by overweight school children than normal-weight children (Bernard, Lavallee, Gray-Donald, Delisle, 1995). The finding from the current study also supports prior research suggesting a protective relationship between fruit consumption and BMI. After adjusting for caloric intake, however, the magnitude of the effect was diminished and no longer significant (Field, Gillman, Rosner, Rockett, and Colditz, 2003).

The current study found that soda consumption was an independent risk factor for overweight. This supports the findings of Ludwig and colleagues' longitudinal trial showing that children $(n=548)$ with higher soda and other sugar-sweetened beverage intakes had a higher mean BMI compared to those with lower intakes. Each additional daily serving of sugarsweetened beverages was associated with an increased risk of obesity of $60 \%$ (Ludwig et al., 2001). Similarly, Berkey and coworkers reported that the consumption of sugar-sweetened beverages was associated with BMI gains during the corresponding year in a prospective cohort study $(n=10,000)$ of boys and girls, age nine 14 years, participating in the U.S. Growing Up Today Study (Berkey et al., 2004).

BMI increased significantly as number of minutes of physical activity per day decreased. These findings are in agreement with those by Patrick and coworkers (2004). These researchers used baseline data for adolescents $(n=878$; ages 11 - 15 years) from the Patient-Centered Assessment and Counseling for Exercise Plus Nutrition Project and identified an inverse relationship between BMI and physical activity levels. Adolescents with a BMI-for-age $>85$ th percentile participated in significantly fewer minutes per day of vigorous physical activity than those with a BMI-for-age $<85$ th percentile (Patrick, Norman, Calfas, Sallis, Zabinski, Rupp, Cella et al., 2004). Utilizing data from NHANES III, Forshee and colleagues also reported a strong negative correlation between BMI and participation in team sports or exercise programs for male and female adolescents (Forshee, Anderson, Storey et al., 2004).

The results of this study supported the research hypothesis that there would be a significant difference in the prevalence of pre-HTN and HTN in school-aged children between those with a BMI-for-age $>85$ th percentile and those 
with a BMI-for-age $<85$ th percentile. As the rate of overweight increased, the rate of elevated blood pressure also increased. The prevalence of elevated blood pressure increased across increasing BMI groups, even within the normalweight percentile range, indicating a step gradient relationship between BMI and blood pressure. These study results support the growing body of literature demonstrating the link between child overweight and elevated blood pressure. Freedman and coworkers, utilizing the Bogalusa Heart Study data, reported that overweight children $(n=9,167$; ages five 17 years) were 4.5 times more likely to have elevated SBP and 2.4 times more likely to have elevated DBP than their leaner counterparts (Freedman et al., 1999). Similarly, Sorof and coworkers (2002) found elevated blood pressure rates to be more prevalent in adolescents with a BMI-for-age $>95$ th percentile $(33 \%)$ than in those with a BMI-for-age $<95$ th percentile $(11 \%)$ in a school-based health screening (Sorof et al., 2002). In a more recent screening, Sorof and colleagues (2004) reported that based on three readings, children $(n=5102$; age $10-19$ years) with a normal BMI ( $<85$ th percentile) had an elevated blood pressure prevalence of $2.6 \%$, compared to a prevalence rate of $10.7 \%$ for overweight children (BMI-for-age $>95$ th percentile). This association held to be significant when adjusted for gender, ethnicity, overweight, and age (Sorof et al., 2004).

SBP was correlated with both fruit and soda consumption, supporting the research hypothesis that there would be significant associations between high blood pressure and dietary factors. Moore and coworkers (2005) reported similar associations among blood pressure and diet. Utilizing eight years of follow-up data from the Framingham Children's study (1986), which consisted of 95 children initially three to five years of age, researchers reported that children consuming more fruits and vegetables or more dairy products during the preschool years had smaller yearly SBP gains throughout childhood. When reaching early adolescence, children with a higher consumption of fruits, vegetables, and dairy products had an adjusted mean SBP (106 \pm $2.9 \mathrm{mmHg}$ ) lower than that of children who consumed lower intakes $(113+1.5 \mathrm{mmHg})$
(Moore, et al., 2005). Simons-Morton and colleagues (1997) found that both SBP and DBP were significantly inversely associated with some micronutrients (calcium, magnesium, and potassium) and fiber in 662 hypercholesterolemic children ages eight to 11 years (SimonsMorton et al., 1997).

Soda was found to be linked to elevated blood pressure in our sample of low income students. These findings support those of Savoca and colleagues (2004) who observed a positive association between blood pressure and soda in adolescents, such that high soda consumption rates are associated with higher blood pressure values. These authors suggest caffeine intake may increase blood pressure and thereby increase the risk of HTN (Savoca et al., 2004).

There were some key limitations to this study. The information regarding dietary and physical activity habits was self-reported. Younger participants may have biased their responses in order to give the "right" answer. Data were used for only one blood pressure screening. According to the updated guidelines for HTN and pre-HTN in children and adolescents (NHBLI, 2004), children should be screened three times before being diagnosed with either pre-hypertension or hypertension. Hence, it is understood that reported rates of pre-HTN and HTN are above actual values.

\section{Conclusions}

At $44 \%$, the rate of at risk for overweight and overweight ( $>85$ th percentile BMI-for-age) for these low-income students is significantly above the national rate of $31 \%$. HTN rates are significantly higher and physical activity levels significantly lower for overweight vs. normal weight children. Fruit and vegetable intake decreased significantly by grade between fifth and eighth grades. Soda was found to be an independent risk factor for overweight. In addition, BMI and soda were found to be risk factors for elevated SBP. These findings suggest that nutrition education and physical activity promotion programs are needed in these school districts. It is recommended that parents, teachers, and school district personnel make efforts to promote physical activity and fruit and 
vegetable consumption among students in and out of school. Efforts also need to be directed at decreasing the availability of soda both at home and at school.

\section{References}

American Heart Association (AHA) (2004). Home page. Retrieved October 12, 2004, from http://www.americanheart.org

Appel, L. J., Moore, T. J., Obarzanek, E., Vollmer, W. M., Svetkey, L. P., Sacks, F. M., Bray, G. A., Vogt, T. M., Cutler, J. A., Windhauser, M. M., Lin, P. H., \& Karanja, N. (1997). A clinical trial of the effects of dietary patterns on blood pressure. DASH Collaborative Research Group. New England Journal of Medicine, 336, 1117-24.

Berkey, C. S., Rockett, H. R., Field, A. E., Gillman, M. W., \& Colditz, G. A. (2004). Sugar-added beverages and adolescent weight change. Obesity Research, 12, 778-88.

Bernard, L., Lavallee, C., Gray-Donald, K., \& Delisle H. (1995). Overweight in Cree schoolchildren and adolescents associated with diet, low physical activity, and high television viewing. Journal of the American Dietetic Association, 95, 800.

California Center for Public Health Advocacy (CCPHA). (2002). An epidemic: Overweight and unfit children in California legislative districts. 2002. Retrieved October 16, 2004 , from http://www.publichealthadvocacy.org

Calvadini C., Siega-Riz, A.M., \& Popkin, B.M. (2000). US adolescent food intake trends from 1965 to 1996. Archives of Diseases in Childhood, 83, 18 -24.

Center for Disease Control and Prevention (CDC). (2004). Surveillance summaries, May 21, 2004. MMWR, 53(No. SS-2).

Field, A. E., Gillman, M. W., Rosner, B., Rockett, H. R., \& Colditz, G. A. (2003). Association between fruit and vegetable intake and change in body mass index among a large sample of children and adolescents in the United States. International Journal of Obesity Related Metabolic Disorders, 27, 821-6.

Forshee, R. A., Anderson, P. A., \& Storey, M. L. (2004). The role of beverage consumption, physical activity, sedentary behavior, and demographics on body mass index of adolescents. International Journal of Journal of Food Sciences and Nutrition, 55(6), 463-78.

Freedman, D. S., Dietz, W. H., Srinivasan, S. R., \& Berenson G. S. (1999). The relation of overweight to cardiovascular risk factors among children and adolescents: the Bogalusa Heart Study. Pediatrics, 103(6 Pt. 1), 1175-82.

Hyson, D. (2002). The health benefits of fruits and vegetables: A scientific overview for health professionals. Wilmington, DE: Produce for Better Health Foundation. Retrieved October 15, 2004, from http://www.ca5aday.com

Keihner, A. J., Foerster, S. B., Sugerman S., Oppen, M., \& Hudes, M. (2002). A special report on policy implications from the 1999 California children's healthy eating and exercise practices survey. Sacramento, CA: California Department of Health Services.

Keihner, A. J., Garbolino, T, \& Hudes, M. (2004). Findings from the 1999 California children's healthy eating and exercise practices survey: Intervention implications and campaign evaluation. Sacramento, CA: California Department of Health Services.

Kuczmarski, R. J., Ogden, C. L., \& Grummer-Strawn, L. M. (2000). CDC growth charts: United States. Advanced Data, 314, 1 -27. Retrieved June 1, 2006, from http://www.cdc.gov/growthcharts

Ludwig D. S., Peterson K. E., \& Gortmaker, S. L. (2001). Relation between consumption of sugarsweetened drinks and childhood obesity: A prospective observational analysis. Lancet, 357, 505508.

Moore, L. L., Singer, M. R., Bradlee, M. L., Djousse, L., Proctor, M. H., Cupples, L. A., Ellison, R. C., (2005). Intake of fruits, vegetables, and dairy products in early childhood and subsequent blood pressure change. Epidemiology, 6(1), 4-11.

Muntner, P., He, J., Cutler, J. A., Wildman, R. P., \& Whelton, P. K. (2004). Trends in blood pressure among children and adolescents. Journal of the American Medical Association, 291, 2107-13. 
Centers for Disease Control and Prevention (CDC). (2004). National health and nutrition examination survey (NHANES) 1999-2000. Retrieved October 15, 2004, from http://www.cdc.gov/nchs/about/major/nhanes/nhanes2003-2004/nhanes03 04.htm

National Heart, Lung, and Blood Institute (NHLBI). (2004). The fourth report on the diagnosis, evaluation, and treatment of high blood pressure in children and adolescents. Pediatrics, August, 114(2).

Ogden, C. L., Flegal, K. M., Carroll, M. D., \& Johnson, C. L. (2002). Prevalence and trends in overweight among US children and adolescents, 1999-2000. Journal of the American Medical Association, 288, 1728-32.

Patrick, K., Norman, G. J., Calfas, K. J., Sallis, J. F., Zabinski, M. F., Rupp, J., Cella, J. (2004). Diet, physical activity, and sedentary behaviors as risk factors for overweight in adolescence. Archives of Pediatric and Adolescent Medicine, 158(4), 385-90.

Savoca, M. R., Evans, C. D., Wilson, M. E., Harshfield, G. A., \& Ludwig, D. A. (2004). The association of caffeinated beverages with blood pressure in adolescents. Archives of Pediatric and Adolescent Medicine, 158(5), 473-7.

Simons-Morton, D. G., Hunsberger, S. A., Van Horn, L., Barton, B. A., Robson, A. M., McMahon, R. P., Muhonen, L. E., Kwiterovich, P. O., Lasser, N. L., Kimm, S. Y. S., \& Greenlick, M. R. (1997). Nutrient intake and blood pressure in the dietary intervention study in children. Hypertension, 29, 930-36.

Sorof, J. M., Lai, D., Turner, J., Poffenbarger, T., \& Portman, R. J. (2004). Overweight, ethnicity, and the prevalence of hypertension in school-aged children. Journal of Pediatrics, 113(3 Pt 1), 475-82.

Sorof, J. M., Poffenbarger, T., Franco, K., Bernard, L., \& Portman, R. J. (2002). Isolated systolic hypertension, obesity, and hyperkinetic hemodynamic states in children. Journal of Pediatrics, 140(6), 660-6.

U. S. Department of Agriculture (USDA). (2004). Pyramid servings data: Results from USDA's 1994-96 Continuing survey of food intakes by individuals. Retrieved October 16, 2004, from http://www.barc.usda.gov/bhnrc/foodsurvey/pdf/3yr_py.pdf

\author{
Author Information \\ Kelley Marty, MS \\ Center for Nutrition and Activity Promotion \\ California State University, Chico \\ Ph.: 530-345-0678 \\ Fax.: 530-898-5283 \\ E-Mail: kmarty@,scnac.org \\ Cindy Wolff, PhD, MPA, RD \\ Professor and Director \\ Center for Nutrition and Activity Promotion \\ E-Mail: cwolff@,csuchico.edu \\ Irene Morgan, RN, PhD, FNP \\ Professor of Nursing \\ School of Nursing \\ California State University, Chico \\ E-Mail: imorgan@csuchico.edu
}

